Hans Kristian Mikkelsen

\title{
Towards the ideal special language translation dictionary
}

\begin{abstract}
In order to approach the ideal special language translation dictionary, a functional approach is preferred to a structural one. Functionality can be measured by means of the relevance principle, known from the theory of relevance. Through a relevance-based analysis of prototypical special language terminological dictionaries and general language translation dictionaries it is concluded that by taking over the relevant criteria from these, it should be possible to conceive the ideal special language translation dictionary.
\end{abstract}

\section{Introduction}

The title of this article may immediately seem quite explicit. This, however, is not necessarily so, and I would be happy to touch on just some of the most important problems that turn up in connection with those dictionaries which are primarily used to translate special language texts from a mother tongue to a foreign language - or vice versa: from a foreign language to a mother tongue. Let me shortly outline the contents of the article.

One of the questions that have to be answered is what we are going to understand by a special language dictionary. I.e., we must classify it as a dictionary type. As a starting point we will follow Franz Josef Hausmann's method of typologization.

As the second point, I shall make a minor digression to Deirdre Wilson and Dan Sperber's theory of relevance. I hope that it will not seem beside the point, all the more so because I think it must fall within the central tasks of the so-called metalexicography to establish connections to other disciplines which might shed new light upon the theory behind dictionaries. In short: I find it relevant to include the relevance theory.

After the typologization and sketching of the actual part of relevance theory, I shall, on the basis of the principle of relevance, treat Eugen Wüster's concept of a prototype terminological dictionary and Hans-Peder Kromann, Theis Riiber and Poul Rosbach's concept of a prototype general language translation dictionary. Finally, I shall try to establish a prototype special language translation dictionary. 


\section{Special language dictionaries as a structural dictionary type}

In the metalexicographical literature, several different models for classification or typologization of dictionaries can be found. The one I choose here as a basis for my understanding of special language dictionaries is the one which can be found in the monumental metalexicographical handbook Hausmann/Reichmann/Wiegand/Zgusta (1989), and which has been written by Hausmann (1989), partly in co-operation with Wiegand. Their classification is characterized by its consequent hierarchical approach and its determination of prototypes or ideal dictionaries. Furthermore, it does not proceed from insignificant features such as the size of dictionaries, be it the amount of lemmata (entries) or the number of pages or volumes. The central criteria for Hausmann are, firstly, the dictionary structure and, secondly, the dictionary function. In accordance with this he operates with a phenomenological and a functional typology. The phenomenological is primary because it is the most evident: one simply looks at the character of the information items recorded in the dictionary, and among these especially at the ones that can be regarded as more essential than others. The functional criterion, which registers how the dictionary is used, is less safe as a means of dictionary typologization because the users may acquire the same information on the basis of different lexicographical information items. E.g., syntactic information can be extracted not only from an explicit syntactic information item but also from other items such as an example. (I want to stress this distinction between the data in the book and the effect for the user. This difference is crucial for my argumentation in the sections to come. Cf. Hausmann/Wiegand 1989:341.) Also, the functional criterion differs from the typological one in that, in principle, it refers not to the dictionary itself, but rather to the activities and the circumstances for which dictionaries serve as a tool. E.g., the function "translation carried out by a student" can draw not only on information excerpted from bilingual dictionaries, but also on information from a wide range of other sources.

The first categorization in the phenomenological typology is into those dictionaries which have the same object language on the lemma side as on the information item side, i.e. the monolingual dictionaries, and those that have a different object language on the "left" and "right" side. Talking about bilingual dictionaries, Hausmann seems for a moment to forget the multilingual dictionaries, i.e. dictionaries with more than two languages involved. Neutrally, one could instead bring them together under the heading "non-monolingual dictionaries". Only, this term would run counter to the markedness of this category. 
The next step in the typological hierarchy is a distinction between general and special dictionaries. Within this opposition, the general dictionaries, both the monolingual and the non-monolingual ones, are unmarked, while the special dictionaries are marked in one way or another. In principle the general dictionaries include all those information item types, which the special dictionaries take up and specialize in. If for a moment one ignores the central item of the general dictionaries, i.e. the definition, most special dictionaries can be understood as an autonomization or absolutization of one of the general dictionary's item types. There are four of these item types: 1) items identifying the lemma form, 2) syntagmatic items, 3) paradigmatic items, and 4) pragmatic information items on the lemma semantics. Orthoepic and orthographic dictionaries are instances of specialization of an item identifying the lemma form, collocational dictionaries specialize a syntagmatic item, while synonym and root dictionaries are specializations within the paradigmatic field. Finally, our subject, special language dictionaries, is an instance of specialization of an item which in general dictionaries appears as so-called field labels or pragmatic items, e.g. "phys." or "tech.", marking that the technical term occurs in a usage area which falls outside standard language. Other "pragmatic" special dictionaries deal with phenomena within the standard language, e.g. dictionaries of foreign words. In order to finish the classification/typology we must mention that some special dictionaries specialize certain lemma types, i.e. categories of entry words. That goes for e.g. prepositional dictionaries, dictionaries of abbreviations, dictionaries of toponyms, etc. Finally, there are two dictionary types which can be related to neither item type nor lemma type, namely the text-related reference books (concordances, indices, etc.) and learner's dictionaries - which as the only type are not defined by means of phenomenological criteria, but by functional criteria.

Hausmann's typology is valid primarily for monolingual dictionaries, but, mutatis mutandis, one can expect it to cover the bi- and multilingual dictionaries as well. The typology is based on the complete item structure of the general dictionary, and every special dictionary type is defined by taking the general dictionary as its point of departure. No wonder that at this level of abstraction one looks in vain for a category like terminological dictionaries - it belongs to the wider category "special language dictionaries". The phenomenological classification can easily be specified to cope with such problems, but it is also possible to stop here, as Hausmann does, and let further elaboration be of a functional kind. The phenomenological typologization thus constitutes the skeleton onto which the functional meat is attached. 
We have now classified the different dictionaries into some superordinate prototypes, based primarily on the structure of the dictionaries. Hausmann's typology is not meant to be realistic in the sense that every single dictionary is a manifestation of a type. Rather, the types are ideal or prototypical in the sense "abstract" or "general", many concrete dictionaries being the results of different type combinations. I would prefer to let Hausmann's structural typology remain as it was intended: as a useful descriptive tool. It is an advantage that the phenomenological typologization is so clear-cut. However, if one is looking for ideal/prototypical dictionaries in the sense "optimal" or "perfect", one has to attack the typologization from a functional angle. Hausmann, on the other hand, finds the functional typology attractive and necessary, but inadequate for the purpose of practical typology which is what is needed in a handbook of dictionaries. The difficulties involved are partly that a functional typology relies on a typology of situations of dictionary use, partly that the same function can be carried out in various ways (Hausmann 1989,970).

In another article Hausmann (1989a) demonstrates that user needs were originally the motivating factors behind the production of dictionaries. Only later, with the Reformation, society's needs for self-documentation began to play a major role. As pointed out by Hartmann $(1989,103)$, however, it is not possible, for lack of a user-oriented history of lexicography, to verify or fault a hypothesis saying that dictionary makers have always made assumptions about their intended audience(s).

As I see it, the main problem with the phenomenological typology is that it focuses on the dictionary from the analyst's / metalexicographer's perspective, thereby ignoring the synthesist / practising lexicographer who is bound to take into consideration what and whom the dictionary is intended for. And that is why this kind of typology offers no help when we are trying to establish the notion of an "optimal dictionary" which must be based on knowledge about the user's status, needs, and skills. The empirical studies of dictionary use are still only in their initial phase. For the time being we shall therefore have to rely primarily on hypotheses about the "pragmatics" of a dictionary. An appropriate hypothesis would be that the dictionary's function, i.e. the way it copes with use, determines its macroand microstructural selection and presentation. If that is true, the outlined phenomenological features are all secondary, as they are derived from functional parameters. 


\section{A relevant detour}

The concepts "relevance", "quantity", and "quality" are well-known in text linguistics and pragmatics, and there should be nothing strange in analyzing them in the context of dictionaries, especially when one bears in mind that dictionaries, as Wiegand (1988) has shown, can be understood as texts with a lot of minor texts - all based on the text constituting features cohesion and coherence. I shall, however, leave this problem undiscussed. Instead, I would like to argue that the relevance theory may be used, not only as an argument in favour of the thesis that it really ís the function that determines selection and presentation, but also a means with which one can evaluate dictionaries, i.e. a tool for dictionary criticism, which is one of the most important fields of the metalexicography. But first a little about relevance theory.

Wilson/Sperber elaborate on Grice's pragmatics/theory of communication. Grice (1975 and 1978) maintains that human communication is governed by the so-called co-operative principle. This principle is based on the simple assumption that the receiver must rely on the sender's sincerity, i.e. that the sender will not say anything contrary to the truth. The co-operative principle consists of four maxims of conversation: namely, a quality, a quantity, a relation and a manner maxim. The maxims can be understood as demands, put to the sender, which the receiver takes it for granted that the sender respects. The maxim of quality says, slightly paraphrased, "Tell the truth!", the maxim of quantity: "Say as much as necessary!", the maxim of relation: "Be relevant!", and the maxim of manner: "Speak clearly!". Of the four maxims the last one seems to drop out, the success of the communication only rarely depending on this maxim. Leech $(1983,99 f f)$ therefore tends to relate it to a pragmatic aspect of another kind (cf. Leech's differentiation of an interpersonal and a textual rhetorics). What I want to stress here, is just that quality, quantity and relevance seem to be the most important maxims.

What Wilson/Sperber do is to argue that it is enough to operate with a demand for relevance, while the demands for quality and quantity become subordinate. Where Grice speaks about a co-operative principle, consisting of four maxims of conversation, Wilson/Sperber, instead, are content with a single relevance principle, the other two maxims maintaining a maxim-like status in relation to the superordinate principle of relevance.

The relevance principle is so strong that one is supposed to attach to any utterance an expectation about its relevance for the receiver. This relevance can be transmitted more or less effectively and economically, and 
this is where quality and quantity come in. Wilson/Sperber $(1990,44)$ claim that relevance becomes greater, firstly, when the contextual effects increase, and, secondly, the processing effort decreases. Or in other words:

The more real information to the receiver, the more relevance, and, the less difficulty for the receiver, the more relevance.

(I should like to stress the already mentioned difference between "(real) information" and "information item". "Information", hence, is not the physical amount of items, but the knowledge it generates.)

\section{Determination of functional prototypes for terminological dictionaries and translation dictionaries}

Let us now return to the point where we left the dictionaries: to their function, selection and presentation. I shall maintain that function of the dictionary, or "genuiner Zweck" as Wiegand puts it, is an aspect of the relevance of the dictionary. The main question is what the individual user can do by means of the dictionary, i.e. in which situations it is a relevant tool. There are, however, some limitations in the possibilities of seeing the dictionaries in the light of the relevance theory because there is one important difference between the material Wilson/Sperber use and a dictionary, namely the fact that the sender (the author of the dictionary) does not form his message to the receiver (the dictionary user) in a concrete situation. Rather, the dictionary is intended to cover abstract or typical situations. When we use the relevance principle, it should be born in mind that it is the type, not the individual case we are talking about. Similarly, the receiver/user of a dictionary is not a specific person as in the typical dialogue between two individuals. Instead, the dictionary user is a generalized person, from whom the sender/author is separated in time and space.

This difference between the abstract and the concrete is crucial. It means that we cannot, as in the concrete situation, simply presuppose that what is mentioned in the dictionary will be both relevant and optimal with regard to contextual effects and processing efforts. On the contrary, we must take into account that the dictionary author far from always chooses the right material for his dictionary or presents it in the best way. And that is why dictionary criticism is such an important part of metalexicography.

If one wants to apply the principle of relevance to dictionaries, one must take the position of the receiver. In other words, the relevance theory is a means of interpretation. I see different ways of applying relevance theory to lexicography, none of which is immediately comparable to the analysis of utterances. 
First of all, one could use it in order to analyze existing dictionaries. A solution akin to the utterance analysis would be simply to accept the dictionary as relevant without reservation. In contradistinction to utterance analysis, where the next step will be the receiver's generation of information, the task for the dictionary analysis would be to identify the user and the activity (/-activities) of using the dictionary in question. In other words the device is:

\section{Always presuppose that the dictionary in question is optimally struc- tured - just go out and find out for which function this can be postulated!}

Hartmann $(1989,103)$ expresses the same approach when he says “... that all the information categories supplied by the lexicographer ... are ipso factu 'useful'". In this way one could, e.g., characterize a dictionary like Høedt et al. (1988) as a solution which comes close to the ideal, when the user, who is anyway fully competent in both mother tongue, foreign language and the subject field, seeks help for an otherwise well-known word which has for the moment slipped his memory. This function is but a single aspect of the translation process, all other aspects, linguistic as well as encyclopedic, being left out. If the user does not need these further information items because his knowledge is perfect, a "memory-supportdictionary" as the one mentioned would be just the right one. No noise arising from information items which deal with other aspects of translation disturbs the user: the selectional and presentational structure is almost maximally simple, deserving the title "word list" rather than "dictionary". The next step in such an approach would, of course, be to evaluate whether the function served is actually worth its own dictionary.

Another problem would be to find out whether the function actually supported by the dictionary coincides with the function intended and even asserted. And here we come to another way of analyzing existing dictionaries by means of relevance theory. Most dictionaries will either in their title or somewhere in their front matter explain for whom and for which purpose(s) they are intended. If they do not explicitly tell about their function themselves, it will normally be possible to unveil it by looking at the structure of the dictionary. The analyst can then simulate a situation where a dictionary with exactly these properties, i.e. with this function, is needed. The conclusions will then reveal whether the dictionary tested solves the problems involved in the situation(s) of use and whether its actual performance corresponds to the performance intended or promised. 
The problem with both these approaches is that they seem to presuppose that every aspect involved in the situation of use (cf. Wiegand 1987,195 "Wörterbuchbenutzungssituation") is well-known to the analyst. If that is true, it ought to be possible to give an "expanded activity description" for the "condensed" one (cf. Wiegand 1987,185). E.g., translation can be seen as an activity, which can itself be shown to cover a lot of minor activities. Unfortunately, the roots of empirical research in lexicography are not yet deep enough. One is therefore largely bound to common sense knowledge about the situations for which dictionaries are made to cater.

However, I do not want to focus here on criticism of existing dictionaries. My aim is more general, namely to outline some of the principal problems that all dictionaries, and especially all special language dictionaries, have to take into account. I will consequently instead take a look at the concepts of a couple of non-existing or existing dictionaries and describe them by means of relevance theory. How can one analyze something that does not exist? Well, of course, that is impossible. It would be more appropriate to talk about another kind of existence. A non-existing dictionary is here understood as a concept of a dictionary, a dictionary in spe. And not just any concept, but a concept with the status of prototype. One way of conceiving the ideal bilingual special language dictionary (/dictionaries) could be to get an impression of the intended user and use of other prototypical dictionaries, the intended user and use being the person and the situation for which the dictionary can be judged relevant. I shall, therefore, sketch two prototypes which, I believe, can serve as landmarks for a definition of a prototypical bilingual special language dictionary.

\subsection{Terminological dictionaries}

A terminological dictionary is comparable to a general monolingual dictionary in that it focuses on the content of the linguistic sign.

I deliberately stress the "languageness" of terminology, thereby taking a position on the eternal problem of distinguishing between linguistic and encyclopedic knowledge. Hupka $(1989,991-992)$ gives an account of this discussion which has mainly occupied linguists and lexicographers who belong to structuralistic schools. Some do distinguish between the linguistic and the encyclopedic, some do not. And among those who do distinguish, the demarcation line is drawn in different ways. Kühn (1989) belongs to both main groups! On the one hand he thinks that there is a difference, only it is hard to make a sharp distinction; on the other hand he maintains that the special language dictionary (in my terms: the terminological dic- 
tionary) can be considered the prototypical encyclopedic dictionary. I.e., when a subject ("Fach") is in question, there is either no difference between linguistic and encyclopedic content — or, the encyclopedic content is so dominant that it leaves no room for linguistic content. Wiegand (1988a) argues that it is just as well possible to distinguish between linguistic and encyclopedic content in special language dictionaries as in general/ordinary language dictionaries. For him the terminological dictionary would probably be an instance of linguistic content, as far as the purpose of the terminological dictionary is to give information about the lemma sign, and not the lemma referent. If this interpretation of Wiegand is right, I fully agree with him.

Perhaps it would be more appropriate to compare a terminological dictionary with a dictionary of foreign words, the main purpose of such a dictionary being to explain to the user what a given more or less unknown word means. A general dictionary also explains ordinary words, and it does not just explain - it also brings information items belonging to the paradigmatic and syntagmatic relations.

Let us regard Wüster's concept of a terminological dictionary as a prototype which it is worth analyzing. What immediately strikes one is its peculiar macrostructural organization: it follows a certain system, and the succession of the dictionary articles reflects the mutual (linguistic) content relations among the terms, a term being a word whose content is fixed by a definition. (Most terminologists, including Wüster, treat the linguistic content as non-linguistic "notions". In my view, this is an example of taking the encyclopedic stand and not the linguistic one which I prefer.) The most important information item in systematic dictionaries is the systematization. In a way the definition, which in alphabetical dictionaries belongs to the microstructure of the dictionary article, has moved to the macrostructure and somewhat outside it: the principles of systematization are explained elsewhere, in an appendix to the dictionary or even beyond the dictionary, e.g. in universal decimal classifications such as those known from library science. This, of course, is not the whole truth. Rather, the system defines the specific linguistic world inside which the individual terms occupy certain positions.

Aside from the term form ("Benennung" in the terminologists' terminology), the microstructure gives an explicit definition of the term meaning as well. Apart from these purely linguistic information items, illustrations referring to the encyclopedic knowledge can be found. 
The macro- and microstructural information items are relevant to both the expert and the layman who is interested in the subject. A vertical reading of the macrostructure offers an insight into the coherence of the central lexical part of a special language, which, in turn, reflects the extralinguistic reality of the subject. A horizontal reading concentrates on the meaning of the individual term, thereby opening to the user the possibility of understanding texts conceived in a special language. In short we can determine the terminological dictionary's (genuine) function as providing cognitive knowledge about a special language. The receiver of this knowledge is, in Kalverkämper's (In print) terms, the educated layman. (Kalverkämper distinguishes between two user-levels: the total layman and the educated layman, thereby leaving out the expert, who in his opinion does not need a dictionary at all. The terminological dictionary for the total layman is alphabetically organized, cf. below.)

Consequently, in the perspective of relevance theory the prototypical terminological dictionary is relevant to a user who is in possession of the basic insight into the subject, which offers him an opportunity to access an onomasiologically arranged dictionary. This arrangement is central when cognition is in focus: it provides the user with the special linguistic context of a given entry. The contextual effects of this macrostructural presentation are thus clearly more extensive than the ones that can be gained in an ordinary alphabetical dictionary. On the other hand, if the user does not possess the qualifications needed in order to handle such a dictionary, he will not have access to its potential information. That is why the total layman is better off with an alphabetically arranged terminological dictionary. Only, the range of contextual effects narrows in with such a solution. It turns out that considerations of use and user tend to clash with each other. When I present Wüster's terminological dictionary as an optimum, it now becomes clear that this goes only for a definite user profile, namely the one characterized as "educated layman", and, perhaps, "expert". As soon as we switch to a lower level of user qualifications, consequences appear in the dictionary structure. I shall, however, not leave out the fact that an alphabetical macrostructure may be more adequate when the dictionary is used as an aid to reading comprehension. In such instances the direct way is from the wording/expression in question to its contents. Nevertheless, the potential amount of information will still be greater in the dictionary with a systematic macrostructure. A change to an alphabetical macrostructure leads to the loss of the position of the term in the language universe of the special subject. A good, alphabetically structured terminological dic- 
tionary presupposes a systematical one, at least theoretically: the definitions given in the microstructure will always ideally depend on a systematical network in order to be coherent and non-homonymous, non-polysemous, and non-synonymous (cf. Arntz/Picht 1989,Ch. IV). An alphabetical terminological dictionary ought not to be the easy solution, i.e. the one chosen in order to avoid the laborious systematization. On the contrary, it ought to be the most complex one, the one actualized by taking the user into special consideration without dropping the functional parameter of use.

The remarks above are valid for monolingual terminological dictionaries, whether definitional or synonymic in form. A characteristic of terminological dictionaries is, however, that they are often multilingual. The translingual and transcultural character of many subjects, especially within the technical and scientific disciplines, makes it possible to append more languages to the same system and the same definitions. The great work load - and expenses - that are taken up by the circumstantial production of a terminological dictionary can thus be reduced by using the same system and the same definitions more than once. That is the method proposed by Wüster: first work out a basic systematical volume including the definitions of term forms from one or a few languages; then compile the term forms from other languages in supplementary volumes simply copying the systematization of the basic volume and referring to the definitions given there.

In spite of this multilingual character, the terminological dictionaries remain relevant only for cognitive purposes. From a translational point of view the value of the terminological dictionaries is limited. As translation starts semasiologically, i.e. with a word form in the source language, the user has to access the dictionary via the alphabetical register. From here he is referred to the systematization which gives the key to an equivalent in the target language. The microstructure does not explain the use of different equivalents (if there are any), the information items supplied thus supporting only expert translation from a foreign language (L2) to a mother tongue (L1). Apart from the translationally awkward macrostructure, the microstructure can be said to be redundant because of the definition which cannot normally serve as an equivalent. Put in the terms of relevance theory, it seems obvious that, on the one hand, the contextual effects of terminological dictionaries are peripheral to translation, and, on the other, the processing effort needed leaves much to be desired. That is not the same as saying that terminological dictionaries are irrelevant for translation, but 
it means that compared to dictionaries tuned to translation they are less relevant.

Sometimes scarce grammatical items, e.g. word class labels, are given in terminological dictionaries. Such items are, of course, needed for communicative purposes such as translation, but again seen in the context of the otherwise cognitive tuning their communicative worth is doubtful. Aberrations of this kind from the prototypical terminological dictionary are at best harmless, but at worst hamper the principal situational function: to provide cognitive knowledge about a special language.

\subsection{General language translation dictionaries}

Let us now for a while leave the special language dictionaries and instead have a look at general bilingual dictionaries. Kromann/Riiber/Rosbach (1984) have, on the basis of fundamental ideas conceived by Scerba and Williams, formulated the thesis about the four dictionaries per language pair. Again relevance and functionality are decisive factors: it is not the same items that, e.g., a Dane needs as an Englishman needs in a Danish-English dictionary. There must, at least ideally, be two Danish-English and two English-Danish dictionaries: an active (L1>L2) and a passive (L2>L1). Tesnière (1958) expresses this situation in an incisive metaphor, when with enthusiasm he writes about Scerba's Russian-French dictionary for Russians. The dictionary is, he says, like a return ticket, a ticket "thereand-back": a Frenchman needs a return ticket Paris-Moscow-Paris, but not Moscow-Paris-Moscow as the Russian does.

We shall take the so-called active-passive-concept as the prototype for a translation dictionary. This concept relies on the user's full competence in his mother tongue, and the lack of it in the foreign language. E.g., there are substantial differences in the presentation of equivalents. Kromann/Riiber/Rosbach assume three types of equivalence: full, partial and zero. The German Braut is a full equivalent of the English bride and fiancée. I.e., Braut is, in comparison with its English equivalents, polysemous, and must be translated in two ways. The German therefore needs a polysemy gloss in his L1 $>$ L2 dictionary, so that he can make the right decision: $<1>$ (am Hochzeitstag) bride and $<2>$ (Verlobte) fiancée. The Danish faster and the German Tante are partial equivalents, and the German needs a compensating gloss both in an L1>L2 dictionary: tante: (väterlicherseits) faster, (mütterlicherseits) moster - and in an L2>L1 dictionary: faster: tante (väterlicherseits), because there are no hyponyms in German. The Dane has no problem translating to and from German, the hyperonym to 
faster and moster, that is, tante, also existing in Danish. There is also considerable difference with regard to the selection of the so-called idiosyncratic syntagms or collocations: in L1>L2 dictionaries they must be included, while they are redundant in L2>L1 ones. E.g., it is important for a German that his L1>L2 dictionary provides him with an item about the English equivalent to auf das Fahrrad aufsteigen, namely to get on the bicycle. On the other hand, this item is redundant for the Englishman because of the transparency of the construction. Thus, it should not take up space in his L2>L1 dictionary. As far as the macrostructure is concerned, the number of lemmata in an L2>L1 dictionary should be greater than in an L1>L2 dictionary, which is due partly to the need for equivalents for dialectal foreign words, the same need normally not arising in L1>L2 translation, partly to the less elaborate microstructure in $\mathrm{L} 2>\mathrm{L} 1$ dictionaries.

In a relevance perspective the last two arguments are motivated differently. The first argument concerns the potential information or contextual effects, while the second one relies on reflections about processing effort. The principles of the ideal L1>L2 and L2>L1 dictionary rely on the wish that the lexicographical items in their selection and presentation should be relevant in a communicative situation of use of the type "translation". As with the two types of terminological dictionaries, the systematical and the alphabetical one, the two types of translation dictionaries are the result of taking into consideration not only the use, but also the user, be that his proficiency level in a subject or in a (foreign) language. Again the use and the user function seem to run counter to each other: the more the translation dictionary has to be adjusted to a lower level translator, the less it seems to be able to cope with real, text-bound translation problems, thus having to concentrate more on generally acceptable solutions (cf. Vermeer 1989). If we say that a bilingual dictionary must concentrate on the situation of use "translation" and the user profile "competent L1-speaker, non-competent L2-speaker", any deviation from these functional characteristics threaten to weaken the relevance of the dictionary, partly by accumulating items with a low degree of contextual effect, and partly by demanding more effort from the user before he can generate the information needed. In fact, Scerba himself did not regard the communicative function of the dictionary as the most important. On the contrary, he focused on its cognitive function connected to L2 learning and, as he saw this activity as throwing light upon L1 as well, also on L1 learning (cf. Mikkelsen In print). So much only to illustrate that one should talk about not one, but several prototypical dictionaries, each adjusted to a broader or narrower type of situation of use and group of potential users. 


\subsection{Special language translation dictionaries}

Now, what could the prototypical/ideal special language translation dictionary look like, i.e. the one whose primary task is to make accessible information with a maximum of contextual effect for special language translation by way of a minimum of processing effort? Well, according to Kromann/Riiber/Rosbach (1984,224), a special language translation dictionary will have to contain exactly the same items as the corresponding general one. Kromann, though, has later modified this attitude, proposing now a bilingual special language dictionary of the "Allbuch-type", i.e. a dictionary that contains not only — as the general one - strict linguistic items, but also encyclopedic items (Kromann/Thomsen 1989,153). The argument is that we must assume that the typical user of the special language translation dictionary, to be sure, is L1 competent, but not necessarily in possession of the subject insight which facilitates a correct interlingual communication, i.e. translation. In my opinion, and on the background of what I have already said about the demarcation of encyclopedic and linguistic knowledge, it would be more appropriate to refer to Spang-Hanssen $(1983,97)$. According to him, language users possess different knowledge, including different knowledge about subjects and the language uses connected to subjects. The relation between general and special language ends up being a question of linguistic authority. The special language authority includes the cognitive knowledge, represented by terminological definitions and systems, but it is not confined to terminology. Special language authority is as much characterized by the communicative knowledge about how the special words and terms combine mutually and with ordinary words (Spang-Hanssen 1983,99).

I shall now, in continuation of Kromann's and Spang-Hanssen's interpretations, introduce a distinction between general language knowledge $(\mathrm{gL})$ and special language knowledge (sL). We may thus, when translation between two languages is in question, talk about four different user competences: gL1, sL1, gL2 and sL2. Moreover, we could further introduce the notions of subject knowledge and subject competence, i.e. the knowledge stemming from the non-linguistic, encyclopedic, "real" world. Hence, a special language dictionary does not automatically include encyclopedic information items, though, of course, it does not exclude them either.

If we stick to the linguistic special language dictionary, "fachliches Sprachwörterbuch" in Wiegand's (1988a) terms, we must operate with, in principle, the above mentioned four different language competences per 
language user. It seems appropriate to let a prototypical special language dictionary concentrate on a user who has gL1 competence, but lacks SL1, gL2, and sL2 competence. This seems to be a very big mouthful for one dictionary, much bigger than e.g. the task of general language dictionaries. But once again relevance and functionality reach out a helping hand. The point is that we must look at the broader context in which the special language dictionary occurs. First of all, we must ask ourselves which linguistic material it would be relevant to select as lemmata for such a dictionary. I have elsewhere (Mikkelsen 1990) argued, that, if expedient, it would be most appropriate to concentrate on a part of a given sublanguage, namely either the part which it has in common with other sublanguages or the part which is specific. We could name these common language and specific language. Now, if we assign the common language of a certain set of sublanguages to the general dictionary, it will be reasonable to say that the special language dictionary can leave out common language in order to concentrate on specific language within one or more sublanguages. The immediate effect is that the lemma stock can be substantially reduced. From the point of view of relevance theory this is tantamount to a reduced processing effort. Provided that the excluded items can be found in a general language dictionary, the reduction affects only redundant information items.

The next question concerns the criteria for lemmatization. I shall propose to proceed the way Gerd (1986) suggests, namely to select the terms within a given subject. If there is no standardized terminology in the subject field, one must choose the words and collocations which function as terms of the subject. I cannot go further into this problem, but just note that one ought to proceed the same way as in terminology work. It is extremely important to place the terms in an overview of the subject (language). This overview can later be placed in the dictionary as an appendix. As a subsidiary advantage of this approach one can combine certain elements in the production of terminological and special language translation dictionaries: the lemma selection is the same. However, this goes neither for the macrostructural presentation, nor for the microstructural selection or presentation of items. The macrostructure must be alphabetical, not systematical as in the terminological dictionary. The relevant microstructure will more or less correspond to the one known from the gL1>gL2 and gL2 $>\mathrm{gL} 1$ prototypes, except of course for the special semantic sL1 glosses. For this purpose the term definition, known from the terminological dictionary, will possibly turn out to be useful, perhaps in a paraphrased form. The colloca- 
tions will be quite central in the special language translation dictionaries. This will be true even more here than in general language translation dictionaries, where, e.g., idiosyncratic collocations could be left out in gL2 $>\mathrm{gL} 1$ dictionaries because of their transparency. Such exemptions cannot be made in sL dictionaries intended for the non-specialist user. In other words, such collocational equivalents in sL1 belong to the central contextual effects of a dictionary like this one.

\section{Conclusions and perspectives}

Two approaches to typologization of dictionaries are presented in this article: the phenomenological and the functional one. The two criteria are totally different. The phenomenological one is based on purely structural features as they are present in the way the material for the dictionary is selected and presented. The functional criteria are pragmatic, concentrating on different elements in the situation of use. It is argued that the phenomenological approach is ultimately secondary to the functional.

Function and relevance are intimately connected, even though they concentrate on different sides of the situation of use. Function is what you are going for, while relevance is what you can use in order to go there.

Special language translation involves four kinds of competence: general language competence in L1, special language competence in L1, general language competence in L2, and special language competence in L2. An ideal dictionary must take into consideration the user's linguistic authority. The proposed concept of special language translation dictionaries concentrates on the specific language, leaving the common language to the general language dictionaries. The intended user is supposed to possess only general language competence in L1 (gL1), which means that the lack of other competences (sL1, gL2, and sL2) must be coped with in the dictionaries. However, the gL2 competence can be regarded as the problem of the general language dictionaries, leaving sL2 and also sL1 competence to the special language dictionaries.

The approach presented and the conclusions open up certain perspectives. First of all I hope to have demonstrated that the essential notions in a use and user oriented approach to lexicography, including metalexicography, is function. The functional parameters "use" and "user" are the ones that (ought to) determine the structure of the dictionaries, i.e. their selectional and presentational characteristics. Furthermore, I hope to have shown that the relevance principle is a useful interpretational tool also in lexicography. In this article I have applied it to concepts of terminological 
special language dictionaries and general language translation dictionaries in order to approach some of the ideal special language translation dictionaries. Finally, I find that both the method and the results presented may furnish the lexicographical criticism of real, existing dictionaries with a solid ground.

\section{Bibliography}

Arntz, Reiner / Heribert Picht (1989): Einführung in die Terminologiearbeit. Hildesheim, Zürich, New York: Georg Olms Verlag. (= Arntz, Reiner / Norbert Wegner (eds.): Studien zu Sprache und Technik, Band 2)

Gerd, Aleksandr Sergeevic (1986): Osnovy naucno-techniceskoj leksikografii. (Kak rabotat' nad terminologiceskim slovarem). Leningrad: Izdatel'stvo Leningradskogo Universiteta.

Grice, H.P. (1975): Logic and conversation. In: P. Cole / J. Morgan (eds.): Syntax and semantics 3: Speech acts. New York: Academic Press, 41-58.

Grice, H.P. (1978): Further notes on logic and conversation. In: P. Cole (ed.): Syntax and semantics 9: Pragmatics. New York: Academic Press, 113-128.

Hartmann, Reinhard Rudolf Karl (1989): Sociology of the Dictionary User: Hypotheses and Empirical Studies. In: Franz Josef Hausmann / Oskar Reichmann / Herbert Ernst Wiegand / Ladislav Zgusta (eds.): Wörterbücher, Dictionaries, Dictionnaires. An International Encyclopedia of Lexicography, First Volume. Berlin, New York: Walter de Gruyter, 102-111. (= Handbücher zur Sprach- und Kommunikationswissenschaft, Band 5.1.)

Hausmann, Franz Josef (1989): Wörterbuchtypologie. In: Franz Josef Hausmann / Oskar Reichmann / Herbert Ernst Wiegand / Ladislav Zgusta (eds.): Wörterbücher, Dictionaries, Dictionnaires. An International Encyclopedia of Lexicography, First Volume. Berlin, New York: Walter de Gruyter, 968-981. (= Handbücher zur Sprach- und Kommunikationswissenschaft, Band 5.1.)

Hausmann, Franz Josef (1989a): Die gesellschaftlichen Aufgaben der Lexikographie in Geschichte und Gegenwart. In: Franz Josef Hausmann / Oskar Reichmann / Herbert Ernst Wiegand / Ladislav Zgusta (eds.): Wörterbücher, Dictionaries, Dictionnaires. An International Encyclopedia of Lexicography, First Volume. Berlin, New York: Walter de Gruyter, 1-19. (= Handbücher zur Sprach- und Kommunikationswissenschaft, Band 5.1.)

Hausmann, Franz Josef / Oskar Reichmann / Herbert Ernst Wiegand / Ladislav Zgusta (eds.)(1989): Wörterbücher, Dictionaries, Dictionnaires. An International Encyclopedia of Lexicography, First Volume. Berlin, New York: Walter de Gruyter. (= Handbücher zur Sprach- und Kommunikationswissenschaft, Band 5.1.)

Hausmann, Franz Josef / Herbert Ernst Wiegand (1989): Component Parts and Structures of General Monolingual Dictionaries: A Survey. In: Franz Josef Hausmann / Oskar Reichmann / Herbert Ernst Wiegand / Ladislav Zgusta (eds.): Wörterbücher, Dictionaries, Dictionnaires. An International Encyclopedia of Lexicography, First Volume. Berlin, New York: Walter de Gruyter, 328-360. (= Handbücher zur Sprach- und Kommunikationswissenschaft, Band 5.1.) 


\section{8}

Hupka, Werner (1989): Das enzyklopädische Wörterbuch. In: Franz Josef Hausmann / Oskar Reichmann / Herbert Ernst Wiegand / Ladislav Zgusta (eds.): Wörterbücher, Dictionaries, Dictionnaires. An International Encyclopedia of Lexicography, First Volume. Berlin, New York: Walter de Gruyter, 988-999. (= Handbücher zur Sprach- und Kommunikationswissenschaft, Band 5.1.)

Høedt, Jørgen et al. (eds.) (1988): IFF fagordbog dansk/engelsk - engelsk/dansk. IFF Ordbøger.

Kalverkämper, Hartwig (1988): Die Fachwelt in der allgemeinen einsprachigen Lexikographie (deutsch — englisch — französisch — italienisch). In: Fachsprache. Internationale Zeitschrift für Fachsprachenforschung -didaktik und Terminologie 10, 98-123.

Kalverkämper, Hartwig (In print): Das Fachwörterbuch für den Laien. In: Franz Josef Hausmann / Oskar Reichmann / Herbert Ernst Wiegand / Ladislav Zgusta (eds.): Wörterbücher, Dictionaries, Dictionnaires. An International Encyclopedia of Lexicography, Second Volume. Berlin, New York: Walter de Gruyter. (= Handbücher zur Sprach- und Kommunikationswissenschaft, Band 5.2.)

Kromann, Hans-Peder / Theis Riiber / Poul Rosbach (1984): Überlegungen zu Grundfragen der zweisprachigen Lexikographie. In: Herbert Ernst Wiegand (ed.): Studien zur neuhochdeutschen Lexikographie V. Hildesheim, New York: Georg Olms Verlag, 159238.

Kromann, Hans-Peder / Knud Troels Thomsen. (1989): Akzente der Fachsprachenforschung von heute und morgen. Bericht vom Kopenhagener Werkstattgespräch 1.-2. Juni 1988. In: Terminologie et traduction 1, 137-160.

Kühn, Peter (1989): Typologie der Wörterbücher nach Benutzungsmöglichkeiten. In: Franz Josef Hausmann / Oskar Reichmann / Herbert Ernst Wiegand / Ladislav Zgusta (eds.): Wörterbücher, Dictionaries, Dictionnaires. An International Encyclopedia of Lexicography, First Volume. Berlin, New York: Walter de Gruyter, 111-127. (= Handbücher zur Sprach- und Kommunikationswissenschaft, Band 5.1.)

Leech, Geoffrey N. (1983): Principles of Pragmatics. London and New York: Longman.

Mikkelsen, Hans Kristian (1990): Fagsprog og almensprog: særsprog og fællessprog. In: LSP Nyhedsbrev 2, 1-6.

Mikkelsen, Hans Kristian (In print): What did Scerba actually mean by "active" and "passive" dictionaries? In: Lexicographica.

Scerba, Lev Vladimirovic (1939): Predislovie ko vtoromu izdaniju. In: Lev Vladimirovic Scerba / Margarita Ivanovna Matusevic (1983): Russko-francuzskij slovar'. Izd. 11-e. stereotipnoe, 6-9 and in: Lev Vladimirovic Scerba (1974): Jazykovaja sistema i recevaja dejatel' nost'. Leningrad: Nauka, 304-312.

Scerba, Lev Vladimirovic (1940): Opyt obscej teorii leksikografii. In: Izvestija AN SSSR, serija literatury i jazyka 3 and in: Lev Vladimirovic Scerba (1974): Jazykovaja sistema i recevaja dejatel' nost'. Leningrad: Nauka, 265-304.

Spang-Hanssen, Henning (1983): Fagsprog og almensprog. In: Skrifter om anvendt og matematisk lingvistik 10. Kфbenhavns Universitets Institut for anvendt og matematisk lingvistik, 85-100.

Tesnière, Lucien (1958): (Ten'er, L.) O russko-francuzskom slovare L.V. Scerby. In: Voprosy Jazykoznanija 6, 41-43.

Vermeer, Hans J. (1989): Wörterbücher als Hilfsmittel für unterschiedliche Typen der 
Translation.In: Franz Josef Hausmann / Oskar Reichmann / Herbert Ernst Wiegand / Ladislav Zgusta (eds.): Wörterbücher, Dictionaries, Dictionnaires. An International Encyclopedia of Lexicography, First Volume. Berlin, New York: Walter de Gruyter, 171-174. (= Handbücher zur Sprach- und Kommunikationswissenschaft, Band 5.1.)

Wiegand, Herbert Ernst (1987): Zur handlungstheoretischen Grundlegung der Wörterbuchbenutzungsforschung. In: Lexicographica 3, 178-227.

Wiegand, Herbert Ernst (1988): Wörterbuchartikel als Text. In: Gisela Harras (ed.): Das Wörterbuch: Artikel und Verweisstrukturen. Jahrbuch 1987 des Instituts für Deutsche Sprache. Düsseldorf: Schwann, 30-120.

Wiegand, Herbert Ernst (1988a): Was eigentlich ist Fachlexikographie? In: Horst Haider Munske / Peter von Polenz / Oskar Reichmann / Reiner Hildebrandt (eds.): Deutscher Wortschatz. Lexikologische Studien. Ludwig Erich Schmitt zum 80. Geburtstag von seinen Marburger Schülern. Berlin, New York: Walter de Gruyter, 729-790.

Wilson, Deirdre / Dan Sperber (1990): Outline of Relevance Theory. In: Hermes 5, 35-56.

Wüster, Eugen (1979): Einführung in die Allgemeine Terminologielehre und Terminologische Lexikographie, 1-2. Wien: Springer-Verlag Wien/New York. (= Schriftenreihe der Technischen Universität Wien 8:1-2). 
